\title{
Evaluating the Oral Health Knowledge and the Status of Visually Impaired Children using Braille
}

\author{
${ }^{1}$ Anand Tavargeri, ${ }^{2}$ Sapna S Kudtarkar
}

\begin{abstract}
Introduction: Oral health has great impact on the overall health and well-being of an individual. The Disability Discrimination Act, 1995 states that there is need to ensure removal of all the barriers to dental care for this group of individuals and provide equal access for all. Hence, the present study aimed to create awareness on the importance of the oral health care needs among visually impaired children.
\end{abstract}

Objectives: To assess the oral health knowledge, attitude and awareness using Braille-scripted questionnaire and to evaluate and correlate the influence on oral hygiene practices following oral health education using Braille-formatted material.

Materials and methods: A total of 100 visually impaired children were selected randomly from two residential blind institutes. Twenty open-ended Braille-formatted questions were scripted in regional language (Kannada) and were distributed to all the children. At baseline, simplified oral hygiene index (OHI-S) was recorded. Children were provided with oral hygiene instructions verbally and in Braille-formatted material individually. At the end of 2 months, the OHI-S index was rerecorded. Data collected were statistically analyzed.

Results: Basic oral health knowledge was fair as evidenced by many children. The study revealed that $67 \%$ of children were aware of the importance of health of mouth and teeth over the health of body. In the present study, $78 \%$ of children cited that mother was the one who takes care of teeth. These dental visits were mostly reported either as attending the dentist whenever they had dental problems (38\%) or as never having visited dentist $36 \%$. The OHI-S scores before and after intervention showed highly statistically significant results $(p=0.001)$.

Conclusion: Visually impaired children showed acceptable improvement following Braille-scripted oral hygiene instructions with the key factor being the repetition and reinforcement of those instructions.

Keywords: Attitude, Awareness, Health, Knowledge, Oral, Visually impaired children.

\footnotetext{
${ }^{1} \mathrm{Head},{ }^{2}$ Postgraduate Student

1,2Department of Pediatric and Preventive Dentistry, SDM College of Dental Sciences \& Hospital, Dharwad, Karnataka India

Corresponding Author: Sapna S Kudtarkar, Postgraduate Student, Department of Pediatric and Preventive Dentistry, SDM College of Dental Sciences \& Hospital, Dharwad, Karnataka India, Phone: +918147268171, e-mail: kudtarkarsapna@gmail. com
}

How to cite this article: Tavargeri A, Kudtarkar SS. Evaluating the Oral Health Knowledge and the Status of Visually Impaired Children using Braille. J Oral Health Comm Dent 2018;12(2):41-46.

\section{Source of support: Nil}

\section{Conflict of interest: None}

\section{INTRODUCTION}

\section{(Braille: Triumph over Darkness)}

Oral health has a profound impact on child's health and quality of life. Children with disabilities and special needs are at greater risk of health problems, require extra help, and rely on others to achieve and maintain good health. ${ }^{1}$

With 7.8 million blind people in India, the country accounts for $20 \%$ of the 39 million blind populations across the globe. ${ }^{2}$ It is estimated that the prevalence of childhood blindness in India is $0.8 / 1000$ children in $<16$-year age group, implying a total of 300,000 blind children in our country. ${ }^{2}$ The control of blindness in children is considered a high priority of the World Health Organization's VISION 2020, The Right to Sight program. ${ }^{3}$ Visual impairment is essentially an umbrella term used to describe the loss of sight that can be a consequence of a number of different medical conditions. People who are visually impaired may feel as though they are incapable of undertaking normal tasks and may have a harder time acquiring and processing information, thus compromising oral hygiene significantly. ${ }^{4}$ The sense of touch is the first sense to be developed during one's life. It continues to be the primary means of experiencing the world through infancy and as well as in childhood. Braille is a tactile writing system used by people who are visually impaired. It is traditionally written on embossed paper. Most of the studies reveal that brain accelerates the sense of vision by accelerating the sense of touch. ${ }^{5}$

Considering the possible difficulties that visually impaired people may encounter, this study was conducted to assess the oral health knowledge, attitude, and awareness of these children using Braille-based questionnaire and to evaluate the oral hygiene practice following oral hygiene instructions in Braille.

\section{MATERIALS AND METHODS}

In the present study, children were randomly selected from two residential schools meant for the blind, these being 
the only schools providing Braille education. Necessary permission from the school principal and written informed consent were taken from both the schools. A total sample size of 100 visually impaired children residing in the school meant for the blind were chosen by purposive sampling method based on the availability of Braille-trained children. Both schools were enrolled in the study with the purpose to assess the information regarding knowledge, attitude, and awareness concerning oral health.

\section{Inclusion Criteria}

- Children of age group 8 to 14 years with visual impairment/total blindness

- Children who can read Braille

\section{Exclusion Criteria}

- Children with any other disability

- Children who could not read Braille

The study was conducted in the course of 8 weeks. ${ }^{6-10}$

\section{First Visit (Interactive Session)}

Before the collection of the data, an interactive session was conducted to understand their level of comprehension. Brief history was taken regarding the oral health practices of the children. Separate oral health education and motivational session was conducted for their caregivers.

\section{Second Visit (Questionnaire and First Clinical Examination)}

Twenty open-ended questions were standardized in English and then scripted in local language. The Brailletyped Kannada-translated structured questionnaire was prepared with the help of Braille-trained school teacher and were distributed among the children and then translated to English by trained investigator. Oral examination was carried out using plain mouth mirror and explorer. The OHI-S index was recorded to assess the oral health status of the children. ${ }^{11}$ Children received one-on-one oral health education and were provided with written material in Braille for self-learning.

\section{Third Visit (Repetition and Reinforcement)}

On the 15th and the 30th days, the children were highlighted on the importance of tooth brushing and proper brushing method. Repetition and reinforcement of the oral health instruction were done.

\section{Fourth Visit (Follow-up)}

The third visit was held on the 60th day after the onset of the study. The purpose of this visit was to estimate the effectiveness of the oral health education using Braille. The OHI-S index was rerecorded to check the oral health status followed by oral health instructions in Braille. . $12-14^{-14}$

\section{Statistical Analysis}

The data obtained were analyzed using the Statistical Package for the Social Sciences (statistics for windows, version 21.0). The p-value was considered to be significant when less than 0.05 (confidence interval of 95\%). Data collected were analyzed using chi-square test to find association between the oral hygiene and about oral health practices and paired t-test was used to find the difference between OHI-S before and after providing oral health instructions.

\section{RESULTS}

In present study, a total of 100 visually impaired children belonging to the age group of 8 to 14 years were enrolled comprising of 58 males and 42 females (Graph 1).

Table 1 describes the chi-square results with respect to oral hygiene status on the knowledge, attitude, and awareness among visually impaired individuals. Table 2 shows the significant difference of the OHI-S scores before and after providing oral hygiene instructions.

Graph 2 shows the oral hygiene status of study subjects before and after intervention. Graph 3 describes the awareness of individuals regarding the oral health.

In the present study, $67 \%$ of the children were aware of the importance of health of mouth and teeth over the health of body; $49 \%$ of children said that there were two sets of dentition. Only $8 \%$ of them knew that there were 20 milk teeth and 32 permanent teeth; $45 \%$ children responded that they cleaned their tongue with their fingers and 33\% used toothbrush and remaining 22\% did not clean their tongue; $60 \%$ of children incorrectly reported that there is no need for regular dental visits.

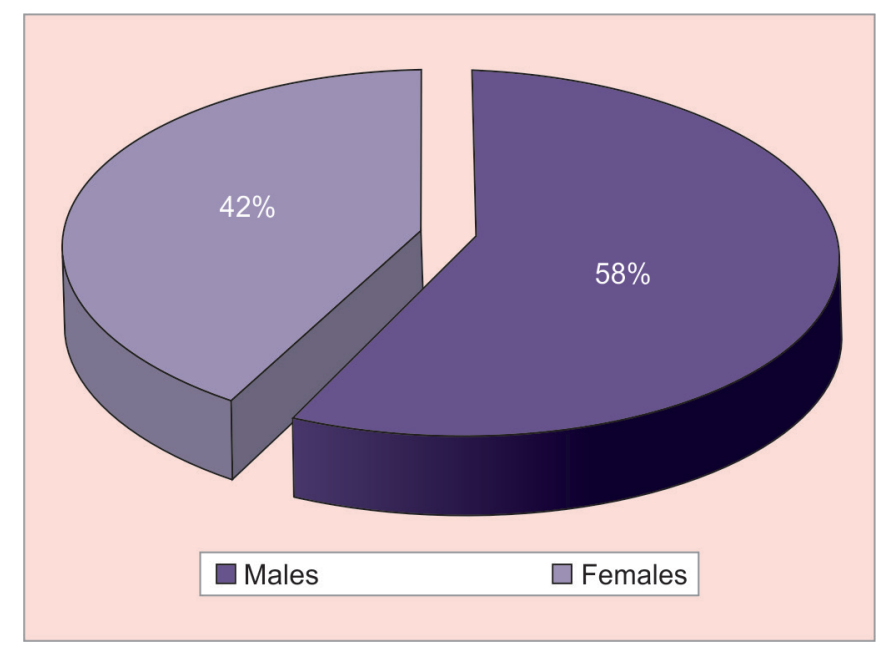

Graph 1: Percentage distribution of children based on gender 
Table 1: Knowledge, attitude, and awareness of visually impaired children about oral health care

Knowledge-based questions
1. Do you know how many sets of dentition in life we do have?

N (Total-100)

Chi-square value

$p$-value
(a) 1
(b) 2
(c) 3
(d) Do not know
13
49
16
22
49
16
22

2. How many number of milk teeth and permanent teeth do we have?
(a) 5 and 24
(b) 20 and 32
(c) 32 and 32
(d) Do not know

3. I brush my teeth to:
(a) Prevent it from tooth decay and gum disease
(b) To achieve cleaner and brighter teeth
(c) To avoid bad breath
(d) Do not know

4. Does the health of mouth and teeth impact the health of your body?
(a) Yes
(b) No
(c) Do not know

5. Do you know who takes care of teeth?
(a) Mother
(b) Dentist
(c) Do not know

Attitude-based questions

1. Do you brush your teeth?
(a) Yes
(b) No

2. How many times do you brush your teeth?
(a) Once a day
(b) Twice a day
(c) More than 2 times

3. When do you brush your teeth?
(a) In the morning
(b) In the evening
(c) Both morning and evening

4. What do you clean your teeth with?
(a) Toothbrush
(b) Finger
(c) Neem stick/datum

5. Do you use toothpaste to clean your teeth?
(a) Yes
(b) No

6. For how long do you brush your teeth?
(a) Less than 1 minute
(b) 1 minute
(c) 2 minutes
(d) Don't know

7. Do you clean your tongue?
(a) Yes, with fingers
(b) Yes, with toothbrush
(c) No

8. How often do you change your toothbrush?
(a) Once every month
(b) Once in 3 month
(c) Once in 6 month
(d) Once in the every year
(e) N/A

7

8

61

24

$2.228^{\mathrm{a}}$

0.898

$7.083^{a}$

0.313

8

61

24

57

57

$2.786^{a}$

0.835

26

16

1

1

67

$5.388^{a}$

0.495

19

14 
(Cont'd...)

Knowledge-based questions

$N($ Total-100)

$\%$

Chi-square value

$p$-value

Awareness-based questions

1. Have you ever felt presence of bad breath?
(a) Yes
(b) No

31

$1.159^{a}$

69

2. Have you ever visited a dentist?
(a) Yes
(b) No

36

3. How often do you think dentist should be visited?
(a) Regularly every 6-12 months
(b) Occasionally
(c) Whenever I have dental pain
(d) Do not know

4. Last time I visited a dentist was
(a) 6 months ago
(b) Last 1-2 years
(c) Last 2-5 years
(d) Never visited

5. Dentists should be visited regularly?
(a) Yes
(b) No

6. Supari (arecanut) chewing is a bad habit?
(a) Yes
(b) No
Efficient cleaning of teeth can be done without using toothpaste?
(a) Yes
(b) No

\section{4}

35

25

36

69

0.885

${ }^{a}$ Cells have expected count less than 5

Table 2: The OHI-S scores before and after intervention

\begin{tabular}{lllllll}
\hline & & \multicolumn{4}{c}{ Paired samples statistics } & \\
\cline { 3 - 6 } & & \multicolumn{4}{c}{ Standard } & Standard \\
dean & $n$ & deviation & error mean & p-value \\
\hline Pair & OHI-S1 & 2.4721 & 100 & 1.31613 & 0.13161 & 0.001 \\
& OHI-S2 & 2.1887 & 100 & 1.24712 & 0.12471 & \\
\hline
\end{tabular}

There is significant difference between OHI-S scores

\section{DISCUSSION}

Ottawa charter defined health promotion as the process of enabling individuals and communities to increase control over the determinants of health and thereby improve their health. ${ }^{7}$ Supporting this statement, the present study was done with the purpose to assess the oral health knowledge and also to educate and promote oral health in visually impaired children. Bhambal et $\mathrm{al}^{15}$ reported that dental treatment is the greatest unattended health of the disabled people, especially in blind who have oral health problems similar to or more than those seen in the general population. In studies done by Ahmad et $\mathrm{al}^{16}$ and Vashisth and Devi, ${ }^{17} 93$ and $72 \%$ of visually impaired children respectively never visited dentist. In contrast to former studies,
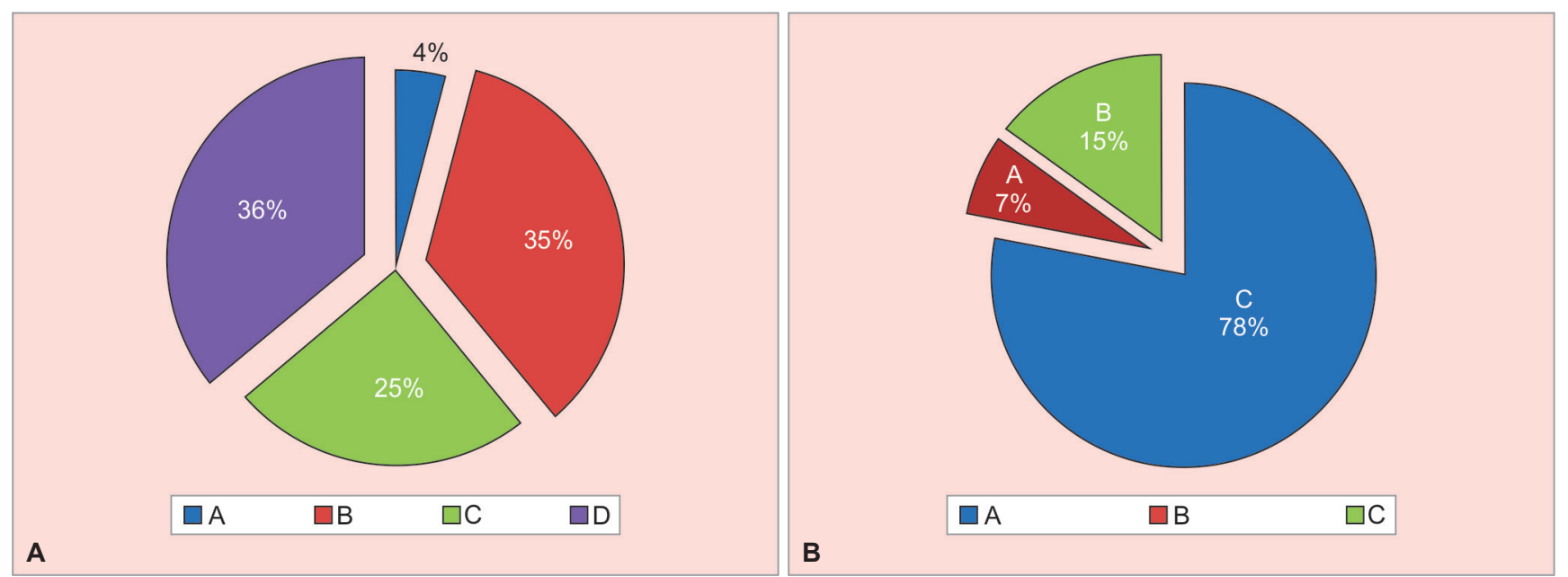

Graphs 2A and B: Awareness of oral health among the visually impaired children 

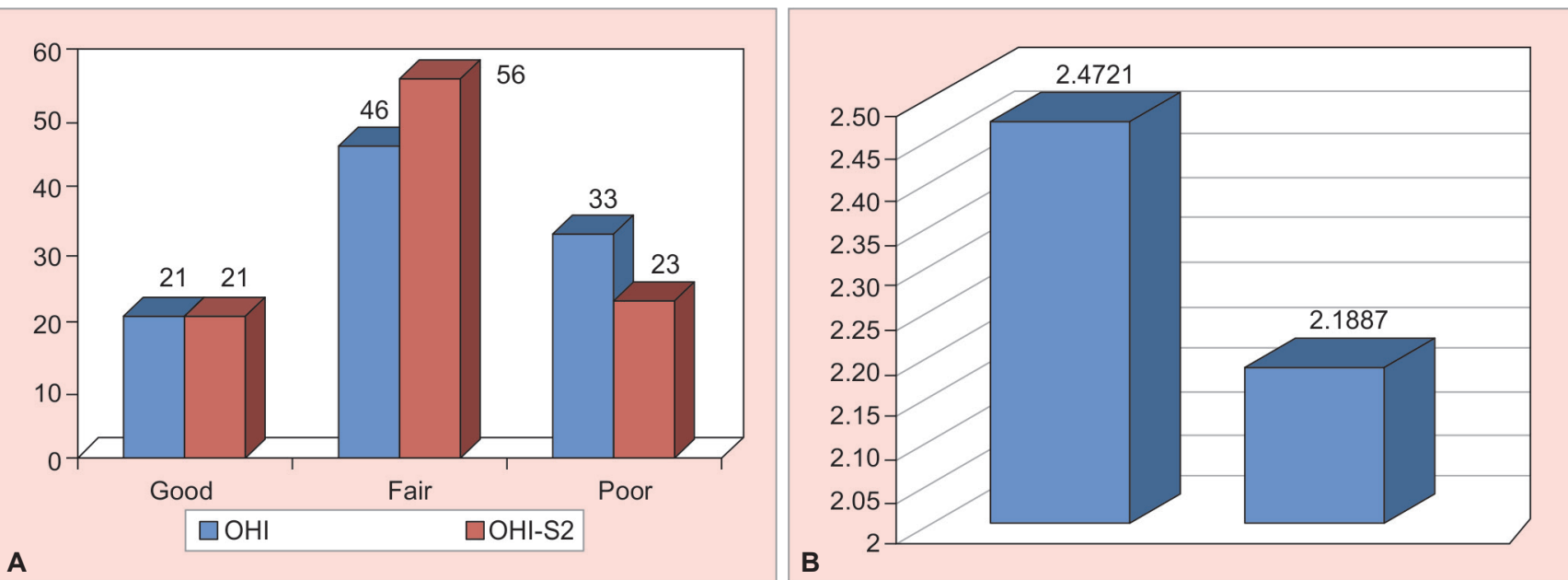

Graphs 3A and B: Oral hygiene status of visually impaired individual classified according to OHI-S before and after intervention

our study revealed that $36 \%$ children never visited dentist. The reason for this difference could be that children in our study were exposed to various dental camps and were known to dentist even though they might have not perceived any treatment. Possibility that most of the people would only seek dental treatment if they were in great pain, otherwise they would think that their oral condition was good because they lack capacity to detect signs of abnormalities within the oral cavity in a visual manner.

Chang and Shih, ${ }^{18}$ in their study, found that students with visual impairments were less knowledgeable about their oral care. In contrast, in our study, majority of the children had fair oral health knowledge. However, there were some concerns over misconceptions; $77 \%$ children stated that efficient cleaning of teeth can be done without using toothpaste and $78 \%$ of children cited that mother was the one who takes care of teeth.

Inappropriate technique and brushing contribute to periodontal problems and other oral health diseases. In a study done by Singh et al, ${ }^{19}$ only $54 \%$ of visually impaired children used toothbrush and toothpaste, but the present study reported with $94 \%$ of children using toothbrush and toothpaste; $4 \%$ used fingers and $2 \%$ used datun. In another study by Solanki et al, ${ }^{20} 74 \%$ of visually impaired children used toothbrush and toothpowder, out of which $90.2 \%$ children cleaned their teeth once daily. Our study observed that oral health behavior was acceptable for frequency of brushing. However, the frequency of brushing once a day ( $83 \%$ ) was higher than as recommended at least twice a day $(17 \%)$. Almost all the children brushed their teeth every day. This may be due to the fact that they stayed in residential school and were motivated by each other. A considerable amount of improvement was observed in the frequency and type of brushing after educating the children through verbal and Braille-formatted instructions.
In blind individuals, the presence of oral malodor indicates periodontal problem. The present study reported that $31 \%$ had experienced bad breath. Similar findings have been reported by Mohd-Dom et $\mathrm{al}^{21}$ where $30.8 \%$ children presented with malodor.

A study done by Ganapathi et $\mathrm{al}^{22}$ showed least reduction in plaque scores in the group provided with Braille pamphlets which was in contrast to our study which illustrated a statistically significant $(\mathrm{p}$-value $=0.001$ ) oral hygiene scores post instructions (Table 2 and Graph 2).

In studies conducted by Nandini ${ }^{23}$ and Ahmad et al, ${ }^{16}$ 8 and $44 \%$ of children respectively reported with poor oral hygiene at baseline, while our study revealed 33\% of the children with poor oral hygiene (Graph 2). The OHI-S score showed significant improvement in plaque scores which changed from poor to fair and fair to good (Graph 2).

A salient factor in our study is the Braille-formatted questionnaire and instructions. According to O'Donnell and Crosswaite, ${ }^{24}$ the visually impaired child's ability to translate verbal instruction is very accurate. Since in our study, we have incorporated both verbal and Brailleformatted instructions, approaching the children individually might have helped us in promoting oral health measures. Thus, we can conclude that our method of imparting oral health education by means of verbal and Braille-formatted instructions successfully helped the children, resulting in enhancement of oral health knowledge and attitude with the reduction in plaque scores.

\section{CONCLUSION}

The present study showed that awareness about the oral health among the visually impaired was fair. Although some misconceptions concerning oral health still prevail, the level of knowledge identified among visually 
impaired children in our study was encouraging. But the need for oral health education among these children aiming at improving oral health knowledge and continuous implementation of oral health promotion programs still exists.

\section{CLINICAL SIGNIFICANCE}

Based on the present study, although children have positive attitude toward oral health, knowledge and practice among children are still below the satisfactory level.

- Establishment of oral health programs that address the oral health promotion and prevention of diseases should be initiated.

- Special considerations must be taken to teach visually impaired about their oral hygiene maintenance.

\section{REFERENCES}

1. Yalcinkaya SE, Atalay T. Improvement of oral hygiene knowledge in a group of visually impaired students. Oral Health Prev Dent 2006;4(4):243-253.

2. Deccan Herald. India accounts 20 per cent of global blind population. New Delhi: Deccan Herald; 2012. [cited 2012 Apr 6]. Available from: http://www.deccanherald.com/240119/ india-accounts-20-per-cent.html.

3. Gilbert C, Foster A. Childhood blindness in the context of VISION 2020-the right to sight. Bull World Health Organ 2001;79(3):227-232.

4. Tagliareni, GF.; Sefo, DL. Teeth look like. Oklahoma: RDH; 2014. [cited 2014 Dec 18]. Available from: http://www. rdhmag.com/articles/print/volume-34/issue-12/features/ teeth-look-like.html.

5. Society for Neuroscience. Blind people perceive touch faster than those with sight. Washington (DC): Society for Neuroscience; 2010. [cited 2010 Oct 18]. Available from: https:/ / www. sciencedaily.com/releases/2010/10/1010261721.htm.

6. Varghese, BJ. Oral health status and attitude of visually impaired children and adolescent in Hong Kong. Hong Kong: University of Hong Kong; 2000. Available from: http:/ / www. hub.hku.hk.

7. Kumar S, Preetha GS. Health promotion: an effective tool for global health. Indian J Community Med 2012 Jan-Mar;37(1):5-12.

8. Bhor K, Shetty V, Garcha V, Nimbulkar GC. Effect of oral health education in the form of Braille and oral health talk on oral hygiene knowledge, practices, and status of 12-17 years old visually impaired school girls in Pune city: a comparative study. J Int Soc Prev Community Dent 2016 Sep-Oct;6(5): 459-464.
9. Williford JW, Muhler JC, Stookey GK. Study demonstrating improved oral hygiene through education. J Am Dent Assoc 1967 Oct;75(4):896-902.

10. Anerud A. The short and long term effect of AV motivation, motivation by dentist and by dental hygienist. J Periodontal Res 1969;4(2):171.

11. Greene JC, Vermillion JR. The simplified oral hygiene index. J Am Dent Assoc 1964 Jan;68:7-13.

12. Radentz WH, Barnes GP, Carter HG, Ailor JE Jr, Johnson RM. An evaluation of two techniques of teaching proper dental flossing procedures. J Periodontol 1973 Mar;44(3):177-182.

13. Vergo T, Ciancio SG, Hausmann E. Instruction in oral hygienea group approach. N Y State Dent J 1974 Oct;40(8):478-481.

14. Kois J, Kotch H, Cormier PP, Laster L. The effectiveness of various methods of plaque control instruction on short-term motivation. A clinical study. J Prev Dent 1978 Mar-Apr;5(2): 27-30.

15. Bhambal A, Jain M, Saxena S, Kothari S. Oral health preventive protocol for mentally disabled subjects-a review. J Adv Dent Res 2011 Apr;2(1):21-26.

16. Ahmad MS, Jindal MK, Khan S, Hashmi SH. Oral health knowledge, practice, oral hygiene status and dental caries prevalence among visually impaired students in residential institute of Aligarh. J Dent Oral Hyg 2009 Aug;1(2):22-26.

17. Vashisth S, Devi A. Oral hygiene practices among visually impaired school-going individuals in Bengaluru city, Karnataka, India. J Cranio-Maxilla Dis 2015 Jan;4(1):39-41.

18. Chang $\mathrm{CH}$, Shih $\mathrm{YH}$. Knowledge of dental health and oral hygiene practices of Taiwanese visually impaired and sighted students. J Vis Impair Blind 2004 May;98(5):1-27.

19. Singh A, Kumar A, Berwal V, Kaur M. Comparative study of oral hygiene status in blind and deaf children of Rajasthan. J Adv Med Dent Sci 2014 Feb;2(1):26-31.

20. Solanki J, Gupta S, Chand S. Comparison of dental caries and oral hygiene status among blind school children and normal children, Jodhpur City Rajasthan, India. Univ Res J Dent 2014 Jan;4(1):22.

21. Mohd-Dom TN, Omar R, Malik NA, Saiman K, Rahmat N. Self-reported oral hygiene practices and periodontal status of visually impaired adults. Glob J Health Sci 2010 Oct;2(2): 184-191.

22. Ganapathi AK, Namineni S, Vaaka PH, Vamsilatha K, Das R, Devi M, Akkaloori A, Kumbakonam A. Effectiveness of various sensory input methods in dental health education among blind children-a comparative study. J Clin Diagn Res 2015 Oct;9(10):ZC75-ZC78.

23. Nandini NS. New insights into improving the oral health of visually impaired children. J Indian Soc Pedod Prev Dent 2003 Dec;21(4):142-143.

24. O'Donnell D, Crosswaite MA. Dental health education for the visually impaired child. J R Soc Health 1990 Apr;110(2):60-61. 